\title{
EVALUATION OF SELECTED PARAMETERS OF MECHANICAL AND PNEUMATIC PRESS DURING GRAPE PRESSING
}

\author{
Pavel Zemanek ${ }^{1}$, Vladimir Masan ${ }^{1}$, Patrik Burg ${ }^{1}$, Bozena Gladyszewska ${ }^{2}$ \\ ${ }^{1}$ Mendel University in Brno, Czech Republic; ${ }^{2}$ University of Life Sciences in Lublin, Poland \\ vladimir.masan@mendelu.cz, patrik.burg@mendelu.cz
}

\begin{abstract}
Modern wine technologies aim for selecting and optimizing the applied technological procedures, including the technical reinsurance of individual operations. One of the key operations, within the wine industry, with a direct impact on the quality of the produced wine is the process of grape pressing. The purpose of pressing is to separate the mold from the processed product by using pressure. The pressing efficiency, exerted by molding, is influenced by the particular type of the pressing device, the varietal properties affecting the consistency of the molded material, the pre-compaction process (crushing, maceration), the thickness of the mold and the number of the pressing cycles. This paper focuses on evaluation of the mechanical horizontal press WOTTLE RS 800 and the pneumatic press ŠKRLJ PST 80, with a volume of 800 litres pressing bins, that were evaluated during the period 2015-2017, while pressing the Sauvignon Blanc and Zweigeltrebe grape varieties. During the evaluation, the main focus was on monitoring the process of pressing, the change of the pressing pressure and its maximum achieved value, the average molding and the performance of the pressers. The results obtained show that, when pressing grapes by a mechanical press, the maximum pressure values are $0.51 \mathrm{MPa}$ while the molding is in the range of $0.748-0.858$ depending on the variety. For the pneumatic press, the maximum pressing pressure was $0.15 \mathrm{MPa}$ and the mold variation was between $0.803-0.865$. The mechanical press performance of the Sauvignon Blanc variety was $268 \mathrm{l} \cdot \mathrm{h}^{-1}, 445 \mathrm{l} \cdot \mathrm{h}^{-1}$ for the pneumatic press. For the Zweigeltrebe variety, the performance of the mechanical press varied at $715 \mathrm{l} \cdot \mathrm{h}^{-1}$ and of the pneumatic press at $7131 \cdot h^{-1}$. The results of the evaluation illustrate the differences arising from the used press and have practical use in wine-making practice and in designing the technological equipment of the wine-growing operations. At the same time, they can serve as inputs when calculating wine production costs.
\end{abstract}

Keywords: viticulture, mechanical press, pneumatic press, press performance.

\section{Introduction}

Careful pressing of grapes directly affects the quality of must and wine. Mechanical systems are generally considered to be less careful, pneumatic presses are gentler, both systems show somewhat different progress of the pressing process. Pavloušek [1] states that the use of higher compression pressure is directly related to the release of undesirable admixtures from the rest of thorns or broken seeds into must. This, among other things, can cause subsequent problems in fermentation, clarification, filtration or stabilization of wine. Darias-Martín et al. [2] argue that the choice of a suitable design variation of the press must be preceded by the knowledge of conditions affecting the yield and quality, maximum production of high quality must, minimum extraction of phenols (type of wine), minimum turbidity and in many cases the minimum pressing time. Similarly, Kraus et al. [3] argue that pressing has to ensure a satisfactory yield of the must, which is determined by the proportion of the must and the original quantity of the processed raw material. Grapes are usually free of thorns and crushed before pressing, although it is also possible to use the technology of pressing whole grapes. Pressing crushed grapes has many technical and technological advantages. In addition to the possibility of using impeller pumps for faster filling of the press bin and achieving higher press performance, it is also influenced by the fermentation time and the acceleration of the pressing process due to draining the juice of the must [4]. Ribereau et al. [5] confirm that low values of compression pressure determine the concentration of glucan in must that is produced from grapes infested by Botrytis cinerea. Darias-Martín et al. [2] state that when more pressure is applied, there is a greater extraction of colored compounds in the brown due to the greater presence of catechins and flavonols.

The thesis aims at comparing the progress of the molding process, yield of juice, achieved performance in two viticultural presses of different design during molding of two different varieties of grapevine.

\section{Materials and methods}

When it comes to the experimental work, two presses with the same volume of the pressing basket (800 liters) were chosen, but constructions and ways of operation were different from the commonly used constructions in medium-sized wine-growing enterprises in the Czech Republic. It refers to the 
mechanical horizontal press WOTTLE RS 800 (Austria) and the pneumatic press ŠKRLJ PST 80 (Slovenia) with a membrane mounted on the half of the inner side of the pressing basket.

Between 2015-2017, with the mentioned presses, pressing of the varieties of Sauvignon Blanc and Zweigeltrebe were monitored and evaluated. Parameters, which were monitored during pressing, are mostly measured values of the compression pressure from the installed nanometers (MPa), the total pressing time $-T_{C}(h)$ that is defined by the sum of duration of the following phases of pressing: $T_{P}$ - filling of the press, $T_{L}$ - stamping including milling of the matolin, $T_{V}$ - empting of the press and $T_{M}$ - remediation and washing. Furthermore, the molding (-), which is expressed as a percentage of the weight of the obtained must to the weight of the processed grapes $-M_{M}(\mathrm{~kg})$. The performance of the presses $-W\left(\mathrm{~kg} \cdot \mathrm{h}^{-1}\right.$ or $\left.1 \cdot \mathrm{h}^{-1}\right)$, which is determined by the amount of must obtained during the pressing cycle, was also determined. Conversion of the weight of the must to the volume of the must was carried out using the bulk density of the must $\left(1065 \mathrm{~kg} \cdot \mathrm{m}^{-3}\right)$.

A statistical analysis was performed using the software package "Statistics 12.0" (StatSoft Inc., Tulsa, Oklahoma, USA). An analysis of variance was performed, and the results were compared using the Tukey's multiple range assay at a significance level $\alpha=0.05$.

\section{Results and discussion}

\section{Evaluation of the pressing process of the Sauvignon variety}

The compression pressure of the Sauvignon varieties in three years is shown in Fig. 1, the resulting values of mold are shown in Table 1.

Components of the ingredients and molding of the Sauvignon variety

Table 1

\begin{tabular}{|c|c|c|c|c|c|c|c|c|}
\hline Year & $\begin{array}{c}\text { Grapes, } \\
\text { kg }\end{array}$ & $\begin{array}{c}\text { Peduncles, } \\
\text { kg }\end{array}$ & $\begin{array}{c}\text { Mixing of } \\
\text { grape skins } \\
\text { and must, } \\
\text { kg }\end{array}$ & $\begin{array}{c}\text { Grape } \\
\text { pomace, } \\
\text { kg }\end{array}$ & $\begin{array}{c}\text { Must, } \\
\text { kg }\end{array}$ & $\begin{array}{c}\text { Must } \\
\text { Average, } \\
\text { kg }\end{array}$ & $\begin{array}{c}\text { Yield } \\
\text { of } \\
\text { juice }\end{array}$ & $\begin{array}{c}\text { Average } \\
\text { yield of } \\
\text { juice }\end{array}$ \\
\hline \multicolumn{9}{|c|}{ Mechanical press WOTTLE RS 800} \\
\hline \multirow{3}{*}{2015} & 1484 & 50 & 1434 & 266 & 1168 & \multirow{3}{*}{1207} & 0.780 & \multirow{3}{*}{0.787} \\
\hline & 1510 & 52 & 1458 & 274 & 1236 & & 0.813 & \\
\hline & 1470 & 48 & 1422 & 253 & 1217 & & 0.777 & \\
\hline \multirow{3}{*}{2016} & 1292 & 48 & 1244 & 274 & 970 & \multirow{3}{*}{950} & 0.752 & \multirow{3}{*}{0.748} \\
\hline & 1350 & 53 & 1297 & 290 & 1007 & & 0.745 & \\
\hline & 1168 & 45 & 1123 & 249 & 874 & & 0.748 & \\
\hline \multirow{3}{*}{2017} & 1410 & 51 & 1359 & 238 & 1122 & \multirow{3}{*}{1113} & 0.795 & \multirow{3}{*}{0.793} \\
\hline & 1480 & 54 & 1426 & 255 & 1171 & & 0.791 & \\
\hline & 1320 & 48 & 1272 & 224 & 1048 & & 0.794 & \\
\hline \multicolumn{9}{|c|}{ Pneumatic press ŠKRLJ PST 80} \\
\hline \multirow{3}{*}{2015} & 1850 & 63 & 1787 & 224 & 1563 & \multirow{3}{*}{1544} & 0.844 & \multirow{3}{*}{0.842} \\
\hline & 1862 & 64 & 1798 & 230 & 1568 & & 0.842 & \\
\hline & 1785 & 59 & 1726 & 225 & 1501 & & 0.840 & \\
\hline \multirow{3}{*}{2016} & 1680 & 62 & 1618 & 269 & 1349 & \multirow{3}{*}{1358} & 0.802 & \multirow{3}{*}{0.803} \\
\hline & 1730 & 64 & 1666 & 253 & 1413 & & 0.816 & \\
\hline & 1650 & 63 & 1587 & 273 & 1314 & & 0.792 & \\
\hline \multirow{3}{*}{2017} & 1800 & 65 & 1735 & 216 & 1519 & \multirow{3}{*}{1502} & 0.841 & \multirow{3}{*}{0.834} \\
\hline & 1760 & 68 & 1692 & 225 & 1467 & & 0.833 & \\
\hline & 1830 & 70 & 1760 & 240 & 1520 & & 0.830 & \\
\hline
\end{tabular}

Time requirement of the working process is determined by the duration of one pressing process $T_{c}$ (h). The values of the time periods of separate phases during pressing and the total time of one pressing cycle of the Sauvignon variety are shown in Table 2.

Table 3 summarizes the performance of the observed presses during pressing of the Sauvignon variety in the monitored years. 

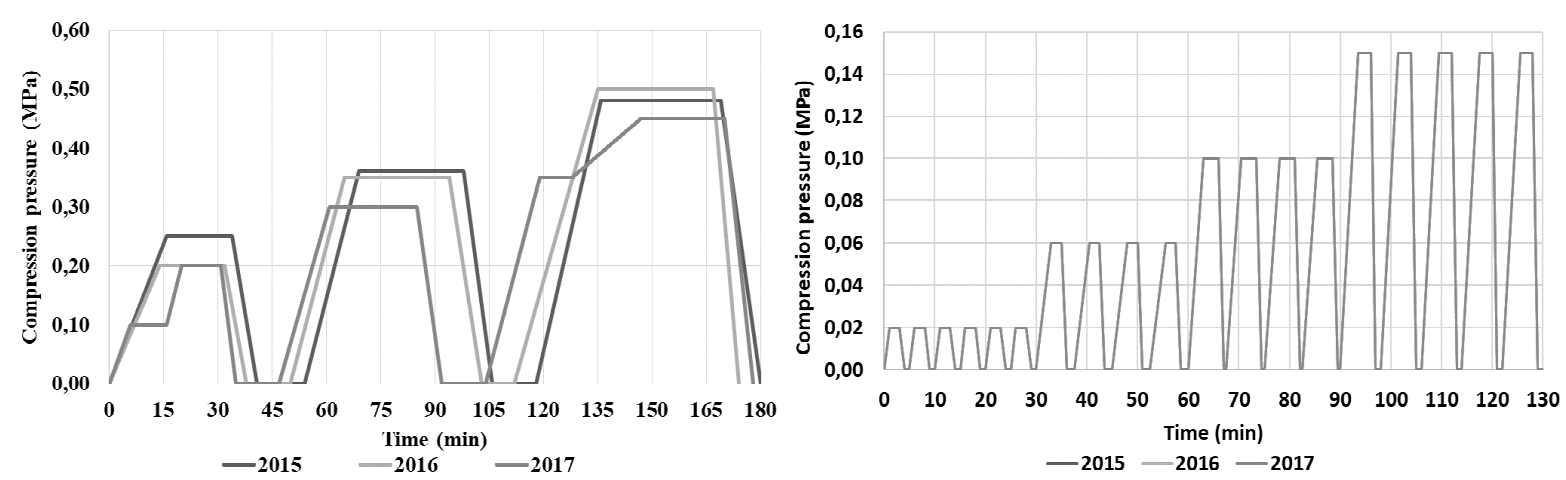

Fig. 1. Comparison of phase of pressing process on three-year mechanical and pneumatic press in Sauvignon variety

Table 2

Time slots of phases and total time of pressing cycle of Sauvignon variety

\begin{tabular}{|c|c|c|c|c|c|c|c|c|c|c|}
\hline \multirow{2}{*}{ Year } & \multicolumn{3}{|c|}{ Mechanical press WOTTLE RS 800 } & \multicolumn{4}{|c|}{ Pneumatic press ŠKRLJ PST 80 } \\
\cline { 2 - 11 } & $\boldsymbol{T}_{\boldsymbol{P}}, \mathbf{h}$ & $\boldsymbol{T}_{\boldsymbol{L}}, \mathbf{h}$ & $\boldsymbol{T}_{\boldsymbol{V}}, \mathbf{h}$ & $\boldsymbol{T}_{\boldsymbol{M}}, \mathbf{h}$ & $\boldsymbol{T}_{\boldsymbol{C}}, \mathbf{h}$ & $\boldsymbol{T}_{\boldsymbol{P}}, \mathbf{h}$ & $\boldsymbol{T}_{\boldsymbol{L}}, \mathbf{h}$ & $\boldsymbol{T}_{\boldsymbol{V}}, \mathbf{h}$ & $\boldsymbol{T}_{\boldsymbol{M}}, \mathbf{h}$ & $\boldsymbol{T}_{\boldsymbol{C}}, \mathbf{h}$ \\
\hline 2015 & 0.30 & 3.00 & 0.25 & 0.33 & 3.88 & 0.33 & 2.17 & 0.28 & 0.30 & 3.08 \\
\hline 2016 & 0.27 & 2.90 & 0.23 & 0.33 & 3.73 & 0.27 & 2.17 & 0.30 & 0.30 & 3.03 \\
\hline 2017 & 0.30 & 2.95 & 0.23 & 0.33 & 3.82 & 0.35 & 2.17 & 0.30 & 0.35 & 3.16 \\
\hline
\end{tabular}

Table 3

Performance during pressing of the Sauvignon variety in the monitored years

\begin{tabular}{|c|c|c|c|c|c|}
\hline \multicolumn{6}{|c|}{ Mechanical press WOTTLE RS 800} \\
\hline Year & $M_{M}, \mathbf{k g}$ & $T_{C}, \mathbf{h}$ & $W, \mathbf{k g} \cdot \mathbf{h}^{-1}$ & $W, \mathbf{l} \cdot \mathbf{h}^{-1}$ & $W_{s}, \mathbf{l} \cdot \mathbf{h}^{-1}$ \\
\hline 2015 & 1207 & 3.88 & 311 & 292 & \multirow{3}{*}{$268 \pm 13$} \\
\hline 2016 & 950 & 3.73 & 254 & 238 & \\
\hline 2017 & 1113 & 3.82 & 291 & 273 & \\
\hline \multicolumn{6}{|c|}{ Pneumatical Press ŠKRLJ PST 80} \\
\hline 2015 & 1544 & 3.08 & 501 & 470 & \multirow{3}{*}{$445 \pm 12$} \\
\hline 2016 & 1358 & 3.03 & 448 & 420 & \\
\hline 2017 & 1502 & 3.16 & 475 & 446 & \\
\hline
\end{tabular}

Evaluation of the pressing process of the Zweigeltrebe variety

Process of the compression pressure of the Zweigeltrebe varieties in the moitored years is shown in Figure 2, the resulting values of mold are shown in Table 4.
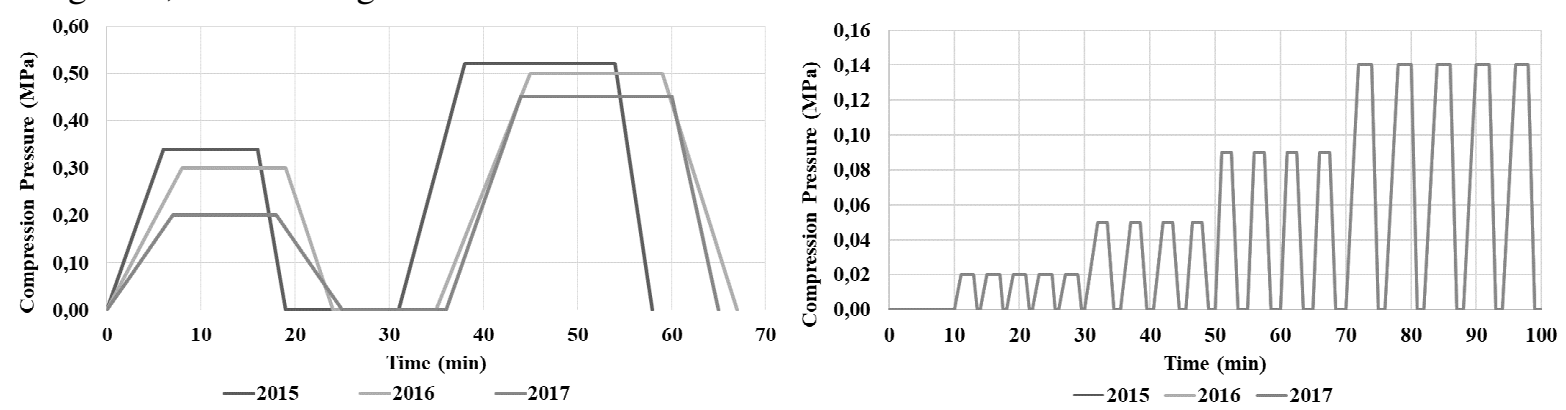

Fig. 2. Comparison of phase of pressing process on three-year mechanical and pneumatic press in Zweigeltrebe variety

In Table 4 the proportions of the components and molding during pressing of the Zweigeltrebe variety are determined. 
Components of the ingredients and molding of the Zweigeltrebe variety

\begin{tabular}{|c|c|c|c|c|c|c|c|c|}
\hline Year & $\begin{array}{c}\text { Grapes, } \\
\text { kg }\end{array}$ & $\begin{array}{l}\text { Peduncles, } \\
\text { kg }\end{array}$ & $\begin{array}{l}\text { Mixing of } \\
\text { grape } \\
\text { skins and } \\
\text { must, kg }\end{array}$ & $\begin{array}{c}\text { Grape } \\
\text { pomace, } \\
\text { kg }\end{array}$ & $\begin{array}{c}\text { Must, } \\
\text { kg }\end{array}$ & $\begin{array}{c}\text { Must } \\
\text { Average, } \\
\text { kg }\end{array}$ & $\begin{array}{c}\text { Yield } \\
\text { of } \\
\text { juice }\end{array}$ & $\begin{array}{c}\text { Average } \\
\text { yield of } \\
\text { juice }\end{array}$ \\
\hline \multicolumn{9}{|c|}{ Mechanical press WOTTLE RS 800} \\
\hline \multirow{3}{*}{2015} & 2250 & 95 & 2155 & 232 & 1923 & \multirow{3}{*}{1877} & 0.854 & \multirow{3}{*}{0.851} \\
\hline & 2200 & 93 & 2107 & 243 & 1864 & & 0.847 & \\
\hline & 2160 & 90 & 2070 & 225 & 1845 & & 0.854 & \\
\hline \multirow{3}{*}{2016} & 2190 & 94 & 2096 & 265 & 1831 & \multirow{3}{*}{1771} & 0.836 & \multirow{3}{*}{0.830} \\
\hline & 2240 & 96 & 2144 & 272 & 1872 & & 0.835 & \\
\hline & 1960 & 92 & 1868 & 258 & 1610 & & 0.821 & \\
\hline \multirow{3}{*}{2017} & 2220 & 94 & 2126 & 222 & 1904 & \multirow{3}{*}{1905} & 0.857 & \multirow{3}{*}{0.858} \\
\hline & 2280 & 96 & 2186 & 228 & 1958 & & 0.858 & \\
\hline & 2160 & 90 & 2070 & 215 & 1855 & & 0.858 & \\
\hline \multicolumn{9}{|c|}{ Pneumatic press ŠKRLJ PST 80} \\
\hline \multirow{3}{*}{2015} & 2850 & 120 & 2730 & 270 & 2460 & \multirow{3}{*}{2430} & 0.863 & \multirow{3}{*}{0.864} \\
\hline & 2780 & 115 & 2665 & 252 & 2413 & & 0.867 & \\
\hline & 2800 & 116 & 2684 & 265 & 2419 & & 0.863 & \\
\hline \multirow{3}{*}{2016} & 2680 & 108 & 2572 & 247 & 2325 & \multirow{3}{*}{2331} & 0.867 & \multirow{3}{*}{0.865} \\
\hline & 2750 & 123 & 2627 & 263 & 2364 & & 0.859 & \\
\hline & 2650 & 110 & 2540 & 235 & 2305 & & 0.870 & \\
\hline \multirow{3}{*}{2017} & 2480 & 105 & 2375 & 238 & 2137 & \multirow{3}{*}{2102} & 0.861 & \multirow{3}{*}{0.852} \\
\hline & 2520 & 120 & 2400 & 245 & 2155 & & 0.855 & \\
\hline & 2390 & 100 & 2290 & 276 & 2014 & & 0.842 & \\
\hline
\end{tabular}

Table 5

Time slots of phases and total time of the pressing cycle of Sauvignon variety

\begin{tabular}{|c|c|c|c|c|c|c|c|c|c|c|}
\hline \multirow{2}{*}{ Year } & \multicolumn{4}{|c|}{ Mechanical press WOTTLE RS 800 } & \multicolumn{4}{|c|}{ Pneumatic press ŠKRLJ PST 80 } \\
\cline { 2 - 11 } & $\boldsymbol{T}_{\boldsymbol{P}}, \mathbf{h}$ & $\boldsymbol{T}_{\boldsymbol{L}} \mathbf{h}$ & $\boldsymbol{T}_{\boldsymbol{V}}, \mathbf{h}$ & $\boldsymbol{T}_{\boldsymbol{M}}, \mathbf{h}$ & $\boldsymbol{T}_{\boldsymbol{C}}, \mathbf{h}$ & $\boldsymbol{T}_{\boldsymbol{P}}, \mathbf{h}$ & $\boldsymbol{T}_{\boldsymbol{L}} \mathbf{h}$ & $\boldsymbol{T}_{\boldsymbol{V}}, \mathbf{h}$ & $\boldsymbol{T}_{\boldsymbol{M}}, \mathbf{h}$ & $\boldsymbol{T}_{\boldsymbol{C}}, \mathbf{h}$ \\
\hline 2015 & 0.58 & 0.97 & 0.30 & 0.47 & 2.31 & 0.52 & 1.67 & 0.42 & 0.43 & 3.03 \\
\hline 2016 & 0.57 & 1.12 & 0.32 & 0.47 & 2.46 & 0.50 & 1.67 & 0.45 & 0.43 & 3.06 \\
\hline 2017 & 0.63 & 1.08 & 0.35 & 0.47 & 2.53 & 0.47 & 1.67 & 0.37 & 0.43 & 2.93 \\
\hline
\end{tabular}

The values of time slots of separate phases during pressing and overall time of one pressing cycle of the Zweigeltrebe variety are shown in Table 5. Table 6 shows summarized results of performance of the observed presses during pressing of the Zweigeltrebe variety.

Table 6

Performances during pressing of Zweigeltrebe variety in the monitored years

\begin{tabular}{|c|c|c|c|c|c|}
\hline \multicolumn{6}{|c|}{ Mechanical press WOTTLE RS 800} \\
\hline Year & $M_{M}, \mathrm{~kg}$ & $T_{C}, \mathbf{h}$ & $W, \mathbf{k g} \cdot \mathbf{h}^{-1}$ & $W, \mathbf{l}^{-1} \mathbf{h}^{-1}$ & $W_{s}, \mathbf{l} \cdot \mathbf{h}^{-1}$ \\
\hline 2015 & 1877 & 2.31 & 812 & 762 & \multirow{3}{*}{$715 \pm 20$} \\
\hline 2016 & 1771 & 2.46 & 719 & 676 & \\
\hline 2017 & 1905 & 2.53 & 753 & 707 & \\
\hline \multicolumn{6}{|c|}{ Pneumatic Press ŠKRLJ PST 80} \\
\hline 2015 & 2430 & 3.03 & 802 & 753 & \multirow{3}{*}{$713 \pm 24$} \\
\hline 2016 & 2331 & 3.06 & 762 & 715 & \\
\hline 2017 & 2102 & 2.93 & 717 & 673 & \\
\hline
\end{tabular}


The summarized measured values about molding achieved during pressing of both varieties on pneumatic and mechanical presses were statistically evaluated by various analysis and the Tukey's multiple range test at a significance level $\alpha=0.05$, as shown in Table 7 .

Table 7

\section{Styles used in this template}

\begin{tabular}{|c|c|c|c|}
\hline Year & Variety & Type of press & Average yield of juice, - \\
\hline 2015 & \multirow{3}{*}{ SVG } & \multirow{3}{*}{ Mechanical } & $0.79 \pm 0.020^{\mathrm{d}}$ \\
\hline 2016 & & & $0.75 \pm 0.004^{\mathrm{e}}$ \\
\hline 2017 & & & $0.79 \pm 0.002^{\mathrm{d}}$ \\
\hline 2015 & \multirow{3}{*}{ SVG } & \multirow{3}{*}{ Pneumatical } & $0.84 \pm 0.002^{\mathrm{abc}}$ \\
\hline 2016 & & & $0.80 \pm 0.012^{\mathrm{d}}$ \\
\hline 2017 & & & $0.83 \pm 0.006^{\mathrm{bc}}$ \\
\hline 2015 & \multirow{3}{*}{ ZW } & \multirow{3}{*}{ Mechanical } & $0.85 \pm 0.004^{\mathrm{abc}}$ \\
\hline 2016 & & & $0.83 \pm 0.008^{b}$ \\
\hline 2017 & & & $0.86 \pm 0.001^{\mathrm{ac}}$ \\
\hline 2015 & \multirow{3}{*}{ ZW } & \multirow{3}{*}{ Pneumatic } & $0.86 \pm 0.002^{\mathrm{a}}$ \\
\hline 2016 & & & $0.87 \pm 0.006^{\mathrm{a}}$ \\
\hline 2017 & & & $0.85 \pm 0.010^{\mathrm{abc}}$ \\
\hline
\end{tabular}

Legend: Data are expressed as means \pm standard deviation, different letters in the same columns represent significant difference $(P<0.05)$.

The obtained results show a statistically significant difference in molding between the two evaluated varieties as well as the presses. In overall, the lower values of molding were determined in a three-year period for pressing of the Sauvignon variety while using the mechanical press and in 2016 when pressed on the pneumatic press. This condition is, mainly in the case of the mechanical press, caused by the phase of the pressing process with a small number of courses of rotating low and high compression pressure according to the following program. This fact is also reflected in the higher performance of the pneumatic press. In addition, white varieties are defined by the character of the pressing product with a higher proportion of berries [6]. This condition is based on the technology of white wine production, where short-term of maceration is followed by pressing of processed raw materials. Also, Darias-Martín et al. [2] states that the pneumatic press allows greater control over the process and by blocking the must outlets of the contact oil it can continue in the press cavity itself. On the other hand, the higher molding value of pressing rmut for red wine production is generally determined by longer time of fermentation, in which partial abortion of meshes occurs. This situation is favourably reflected in the higher performance of both presses. Higher values of molding and performance in pressing of fermented red rmut are confirmed, for example, by Kraus et al. [3] or Steidl [7].

The evaluation shows that the highest compression pressures have been achieved at the mechanical press of 0.50-0.52 MPa in 2015. Altman and Bauer [8] and Steidl [7] consider pressing at a pressure higher than $0.8 \mathrm{MPa}$ to be unpredictable. The mechanical press did not exceed this value. For practical operation of the mechanical press it is convenient to control the pressing process manually and not to exceed the stated pressure values. Meidinger and Altman [9] and Bauer [8] jointly state the limit for gentle pressure on the pneumatic press at 0.20 MPa. The highest measured pressure on the pneumatic press reached 0.15 MPa using the automatic program. Maggu et al. [10] state that the amount of pressure during pressing is an important parameter determining the final composition of the juice for winemaking.

The values of the molding found in the evaluation of both presses are fairly balanced in each year. At the same time, however, each phase shows the same or very similar course of the pressing process in the individual phases. For the pneumatic press, the course was always the same. From the technological and organizational point of view, the achieved performance is of great importance to the press user [11]. For the Sauvignon variety, the performance of the mechanical press was at the $268 \mathrm{l} \cdot \mathrm{h}^{-1}$ and it was significantly higher for the pneumatic press $445 \mathrm{l} \cdot \mathrm{h}^{-1}$. This difference is mainly 
caused by the design of the system, allowing rapid change of phases with low and high pressures. For the Zweigeltrebe variety, the performance of the two presses was comparable and ran at a $715 \mathrm{l} \cdot \mathrm{h}^{-1}$ for the mechanical press at a $7131 \cdot h^{-1}$ for the pneumatic press.

\section{Conclusions}

The paper presents the results of 3 years of experimental monitoring of two kinds of presses used in wine factories.

1. During pressing the Sauvignon and Zweigeltrebe varieties in the years 2015, 2016 and 2017, the pressing process, molding and performance on the mechanical and pneumatic presses were monitored. During pressing, the mechanical press had a pressing pressure of $0.50 \mathrm{MPa}$ and molding of $0.75-0.85$. For the pneumatic press, the maximum pressing pressure was $0.15 \mathrm{MPa}$ and molding was $0.80-0.87$.

2. During pressing, the performance of the mechanical press at the Sauvignon variety was $2681 \cdot h^{-1}$ and the performance of the pneumatic press was $445 \mathrm{l} \cdot \mathrm{h}^{-1}$. For the Zweigeltrebe variety, the performance of both presses was comparable and ranged from 713-715 $1 \cdot \mathrm{h}^{-1}$.

3. The results of the work can be used in winemaking practice, for designing the technological equipment of wine-growing plants and in the calculation of the wine production costs. At the same time, they can serve as inputs for calculating the wine production costs.

\section{Acknowledgements}

This paper was supported by the project CZ.02.2.67/0.0/0.0/16_016/0002366 Infrastructure for competitive graduate of the Mendel University in Brno, this is co-financed from Operational Programme Research, Development and Education.

\section{References}

[1] Pavloušek P. Výroba vína v malovinařství (Production of wine in small viniculture). 2. Updated and extended edition. Prague: Grada, 2010. 120 p. (In Czech).

[2] Darias-Martín J.J., Rodríguez O., Díaz E. etc. Effect of skin contact on the antioxidant phenolics in white wine. Food Chemistry, vol. 71, 2000, pp. 483-487.

[3] Kraus V., Hubáček V., Ackermann P. Rukovět' vinaře (Winegrower's hand). 1. edition, Prague: Brázda, 2000. 262 p. (In Czech).

[4] Burg P., Zemánek P. Pneumatický lis a jeho konstrukce (Pneumatical press and its construction). Vinařský obzor, vol. 4, 2010, pp. 176-178. (In Czech).

[5] Ribéreau-Gayon P., Dubourdieu D., Donèche B. Handbook of enology. 2nd ed. Hoboken, NJ: John Wiley, 2006. 497 p.

[6] Marais J. Effect of grape temperature, oxidation and skin contact on Sauvignon blanc juice and wine composition and wine quality. S. Afr. J. Enol. Vitic., 1998, vol. 1, pp. 10-16.

[7] Steidl R. Sklepní hospodárství (Wine cellar production). 1. ed. Valtice: National salon of wines, 2002. 307 p. (In Czech).

[8] Altman H., Bauer K. Kellerwirtschaft: Lern und Arbeitsbuch für Landwirtschaftliche Fachschulen (Wine cellar production: learning and workbook for agricultural colleges). 4. Aufl. überarb. Wien: Österreichischer Agrarverlag, 1993. 234 p. (In Germany).

[9] Meidinger F. Die Entwicklung der Pressentechnik bis zur pneumatischen Grossraumpresse mit Ergebnissen und Auswertungen vom Herbst 1977 (The development of the press technology up to the pneumatic large space press with results and evaluations from the autumn 1977). Der Deutsche Weinbau, 1978, vol. 33, pp. 1228-1232. (In Germany).

[10] Maggu M., Winz R., Kilmartin P.A. etc. Effect of Skin Contact and Pressure on the Composition of Sauvignon Blanc Must. J. Agric. Food Chem., vol. 55, 2007, pp. 10281-10288.

[11] Yokotsuka K. Effect of press design and pressing pressures on grape juice components. Journal of Fermentation and Bioengineering, vol. 70, 1990, pp. 15-21. 